\title{
Pilar Quintana y Melba Escobar. Disensos y consensos en las novelas La perra (2017) y La mujer que hablaba sola (2019)
}

\author{
Pilar Quintana y Melba Escobar. Dissent and \\ Consensus in Novels La perra (2017) and La mujer \\ que hablaba sola (2019)
}

\begin{abstract}
Resumen
Las poéticas de Pilar Quintana (1972) y de Melba Escobar (1976) ubican al lector en un espacio y tiempo reconocibles: se enraízan en regiones de Colombia y en problemáticas sociales contemporáneas. A ambas autoras les interesa tejer la estética de su ficción enfocando el punto de vista de las mujeres y su diferenciación en la escala social por razones de raza y clase. Sin embargo, afirmamos que la propuesta ético-estética de cada una de las autoras es bien diferente y que cada una de ellas configura una manera particular de comprender la violencia y el papel de la mujer en los conflictos sociales. Acudiendo a ideas y conceptos devenidos del feminismo este artículo pretende exponer las afinidades y diferencias entre las poéticas de cada una de las autoras e interpretar los disensos (Rancière) o formas en que cada una de ellas configura en su trabajo de ficción jerarquías, marcos de referencias, formas de interpretación o representaciones tradicionales de las mujeres.
\end{abstract}

Palabras claves

ficción, consensos, disensos, feminismo, mujeres escritoras.

\begin{abstract}
The poetics of Pilar Quintana (1972) and Melba Escobar (1976) place the reader in a recognizable space and time: they are rooted in regions of Colombia and in contemporary social problems. Both authors are interested in creating the aesthetics of their fiction by focusing on the point of view of women and their differentiation on the social scale for reasons
\end{abstract}


CATEDRAL TomAda: Revista de crítica literaria latinoamericana / Journal of Latin American Literary Criticism Pilar Quintana y Melba Escobar. Disensos y consensos en las novelas La perra (2017) y La mujer que hablaba sola (2019)

of race and class. However, we affirm that the ethical-esthetic proposal of each of the authors is very different and that each of them sets up a particular way of understanding violence and the role of women in social conflicts. Going to ideas and concepts derived from feminism, this article aims to expose the affinities and differences between the poetics of each of the authors and interpret the dissents (Rancière) or ways in which each of them reconfigures in his work of fiction hierarchies, frames of references, forms of interpretation or traditional representations of women.

Keywords fiction, consensus, dissensus, feminism, women writers.

\section{Pilar Quintana y Melba Escobar: sus disensos y el mundo de lo sensible}

Una particularidad de las letras colombianas está dada por su relación directa con los hechos traumáticos de la guerra interna. La violencia, como categoría narrativa e histórica, se concreta en la Guerra de los Mil Días, La Violencia política entre liberales y conservadores, el conflicto armado entre guerrilla, ejército y paramilitares, el narcotráfico y las mafias (Español 123-4). En efecto, encontramos una variada y muy diversa producción narrativa tanto de autores como de autoras que se han interesado por representar literariamente hechos históricos concernientes a la violencia que ha vivido el país a lo largo de su historia. Sin embargo, como lo asegura Capote Díaz (2016) la producción literaria femenina que reescribe la violencia ha sido sistemáticamente invisibilizada y excluida de los cánones elaborados por los críticos violentólogos en el terreno literario (164). La misma suerte de exclusión ha ocurrido con los muy diversos géneros y temas literarios que han trabajado autoras colombianas en distintas épocas. Sin embargo, gracias a algunas investigaciones que apuntan a recuperar y visibilizar la literatura escrita por mujeres hay lugar a una desestabilización y reconfiguración del canon. ${ }^{1}$ Evidentemente, la inclusión de autoras que por razón de su género habían estado

${ }^{1}$ Recientes trabajos se están encargando de desenterrar, visibilizar y darle lugar a la literatura escrita por mujeres que ha sido sistemáticamente silenciada por la crítica especializada. La obra literaria de autoras tales como: Francisca Josefa de la Concepción del Castillo y Guevara o la Madre Castillo (1671 - 1742), Soledad Acosta de Samper (1833-1913), Elisa Mujica (1918-2003), Meira del Mar (1922-2009), Marvel Moreno (1939-1995), entre otras, ha reeditada y resignificada. 
ignoradas logra reconstruir un relato más diverso de toda nuestra literatura (véase Alzate; Jaramillo et al.).

Este contexto actual reivindicatorio no es baladí, por el contrario, es producto de una lucha, permanente y nada neutral, que desde hace muchos años lleva a cabo el feminismo ${ }^{2}$, el cual, tomándonos el riesgo de generalizar, podríamos afirmar que aspira a visibilizar la agencia de las mujeres al tiempo que pretende desestabilizar la estructura patriarcal que prevalece en los diversos ámbitos sociales y de poder. En efecto, nuestra propuesta es la de enmarcarnos en el feminismo, en algunas de sus ideas y conceptos, para comprender el lugar que ocupan las autoras Pilar Quintana (1972) y Melba Escobar (1976) en el panorama literario colombiano, así como el significado de sus respectivas ficciones: La perra (2017) La mujer que hablaba sola (2019).

A la luz de estos planteamientos afirmamos que las escritoras Quintana y Escobar, como también sus obras, asumen posturas identificables con lo que el filósofo Jacques Rancière (1996) refiere como una postura política. Ellas asumen en su trabajo de ficción un disenso frente a las violencias de género que acontecen en una sociedad identificable con la cultura patriarcal de la contemporaneidad colombiana. En este sentido, y como lo presentamos en este escrito, las novelas $L a$ Perra de Pilar Quintana, y La mujer que hablaba sola de Melba Escobar, se desmarcan de formas habituales de representación de la violencia. Pues las novelas referidas coinciden en que la narración ya no se centra en la representación o reescritura de acontecimientos históricos concernientes a la violencia en Colombia (asociada al conflicto armado entre el Estado y los grupos armados, el narcotráfico y/o las mafias), sino en la construcción de personajes femeninos constreñidos en sus comportamientos por causa de un ambiente social impregnado de violencia y hostilidad que condiciona la vida, incluso, la intimidad de las protagonistas. De

${ }^{2}$ En rigor, existen feminismo(s): el radical, el liberal, el eco-feminismo, el de las activistas indígenas o campesinas, por nombrar solo algunos. Sin embargo, utilizamos el singular "feminismo" para referirnos al movimiento de mujeres que ha desembocado en teorías y conceptos que articulan una práctica de los derechos, pero sin ahondar en el mosaico de estrategias e ideologías que hay dentro del movimiento. 
modo que en la novela de Quintana como en la de Escobar, aunque la violencia es un eje de la narración, no es el centro de la trama sino su detonante y en esto ambas novelas se apartan de ciertas narrativas memorialistas y testimoniales de la literatura colombiana cuyo interés ha girado, siguiendo a Lucía Ortiz (2000) o Sklodowska (1992), ora en construir versiones alternativas al relato oficial de la violencia en Colombia, ora en dejar testimonio de vidas y/o acontecimientos históricos violentos que han sido invisibilizados o dejados en el olvido.

La propuesta estética de Escobar explora la relación entre la violencia y el impacto particular y diferenciado que ésta tiene en la protagonista, ya que la afecta a ella de forma específica en sus proyectos de vida llegando incluso a afectarla a un nivel íntimo. En el caso de Quintana, su estética explora la relación entre maternidad y deseo, en un territorio donde la violencia se mimetiza con la selva y el mar influyendo de un modo particular en el destino de la mujer protagonista. Este interés por indagar en la ficción aspectos diferenciales de la violencia y los efectos que puede tener en las mujeres las micro violencias en sus cuerpos y sentimientos puede entenderse como una postura de compromiso que caracteriza a cada una de las autoras. En La perra, de Quintana, como en La mujer que hablaba sola, de Escobar, el interés por hacer ficción está atravesado por una visión de género, razón por la cual en el centro de la narración hallamos a mujeres -las protagonistas en cada una de las novelas-. Ellas habitan territorios identificables en el mundo sensible (Rancière), ya que en cada una de las novelas las protagonistas viven en una región reconocible para el lector, a quien le es posible identificar las referencias al territorio colombiano marcado con problemáticas contemporáneas: en La Perra de Quintana, es rastreable el pacífico colombiano, y en La Mujer que hablaba sola de Escobar, la ciudad de Bogotá.

En vía de presentar cómo cada una de las autoras y sus respectivas obras narrativas articulan su disenso, comencemos por abordar este concepto propuesto por Rancière y que comienza por referirse a lo que él llama el reparto de lo sensible, esto es, el lenguaje como configurador de mundos. El reparto de lo sensible está ligado a las maneras de decir, de ver y de hacer, que distribuyen nuestro orden 
social, las relaciones entre los espacios donde se hace tal o cual cosa y las capacidades vinculadas a ese hacer (58-60). Esta categoría de pensamiento que propone el francés invita a preguntarnos: ¿qué voces son las que se escuchan en la sociedad?, ¿quiénes forman o establecen la visión del mundo tal y como se nos presenta con sus clasificaciones, divisiones y jerarquías? Para Rancière todo orden social, tanto el que llamamos real como el que se configura en la ficción, es producto de estos modos de hacer, de decir y de ver, pues estas formas son lenguaje y éste es el que condiciona la manera de estar en el mundo. De modo que la invitación del filósofo consiste en dejar de diferenciar entre un tal "mundo de ficción" y un "mundo real", por el contrario, lo que él llama el orden o partición de lo sensible, es todo aquello que da significados o sentidos a las maneras como se habita el mundo. Así que la ficción sería solo un campo más de reproducción o de ruptura de significados los cuales tienen efecto en las maneras habitar el mundo. La ficción pues, no es tanto la creación de un mundo imaginario ajeno al real sino la labor de disentir, de transformar modos de representación de los sensible y formas de enunciación.

La propuesta de Rancière es alentadora porque en ella el orden de lo sensible siempre es susceptible de ser hendido o fracturado, en otras palabras: el orden social jerarquizado, blanco y patriarcal es posible de ser reconfigurado. La literatura y el arte en general serían las formas más eficaces de alterar esos órdenes preestablecidos y jerárquicos. Por ejemplo, por medio de cambios o alteraciones en la narración a diversos niveles es posible alterar lo que parece inalterable, transformar significados, hacer ver las contradicciones de aquello que se presenta como perfecto y consensual. Es en este punto en que ocurre el disenso o lo que Rancière llama la actividad de disentir que es: "[...] la que desplaza a un cuerpo del lugar que le estaba asignado o cambia el destino de un lugar; hace ver lo que no tenía razón para ser visto, hace escuchar un discurso allí donde sólo el ruido tenía lugar, hace escuchar como discurso lo que no era escuchado más que como ruido" (45). 
CATEDRAL TOMADA: Revista de crítica literaria latinoamericana / Journal of Latin American Literary Criticism Pilar Quintana y Melba Escobar. Disensos y consensos en las novelas La perra (2017) y La mujer que hablaba sola (2019)

Acoplando la definición de disenso del filósofo francés a la experiencia histórica de lucha femenina merece la pena referirnos a Silvia Federicci que en su Calibán y la bruja. Mujeres, cuerpo y acumulación originaria (2004) afirma que su escrito, entroncado en el saber feminista, "se niega a identificar el cuerpo [de las mujeres] con la esfera de lo privado y, en esa línea, habla de una política del cuerpo" (30). En efecto, la batalla del feminismo ha consistido en un disenso categórico del lugar al que históricamente se ha relegado a la mujer por razón de su cuerpo. Disentir no consiste simplemente en reclamar unos derechos, sino más bien significa exhibir o exponer la contradicción e hipocresía del discurso de los derechos con respecto a su práctica. El disenso es una actividad política, concepto éste que Rancière no asocia con lo burocrático sino con la posibilidad del arte para transformar, porque desordena la rígida división de los cuerpos y su asignación o destino a determinado lugar y tarea (44-5).

Dicho esto, pasamos a plantear cómo las escritoras Quintana y Escobar y sus novelas se sitúan políticamente en disenso reconfigurando su más próximo mundo sensible, el de la contemporaneidad colombiana. Lo anterior significa comprender la postura política de las autoras y la de sus respectivas obras ya que el mundo que cada una de ellas compone en su escritura hace parte de su disenso o de su manera de posicionarse en lo social.

Comencemos por señalar que los respectivos años en que fueron publicadas las novelas de nuestro interés coinciden ambas fechas (2017 y 2019) con dos momentos de disenso de un buen grupo de autoras colombianas contra entes de la institución literaria ${ }^{3}$ que las han excluido de prestigiosos eventos literarios. En el año 2017, fecha de publicación de la novela de Pilar Quintana, La perra, la protesta se dirigió contra el Ministerio de Cultura colombiano cuando seleccionó a una delegación de diez autores colombianos, todos del género masculino, para que

${ }^{3}$ Ana Gallego (2014) basándose en Beatriz Sarlo dice que la "«institución» se refiere a la academia, los programas educativos, los manuales de enseñanza, las antologías, el canon, la industria editorial, las revistas, los medios de comunicación, los premios literarios, el criterio de autoridad de escritores, críticos y profesores, las citas y demás agentes del aparato literario, que constituyen formas de transmisión del poder hegemónico" (2) 
asistieran a La Bibliothèque de l'Arsenal de París donde se daría a conocer el panorama actual de literatura colombiana. Ante la ausencia de mujeres escritoras colombianas en aquella selección, un número importante de autoras respaldadas por sus pares latinoamericanas y españolas, firmaron un manifiesto con el lema "Colombia tiene escritoras", en el cual expresaron la inercia del machismo en los procesos de selección, al tiempo que resaltaban la calidad y profesionalidad de la escritura femenina. En el manifiesto afirmaron el derecho que tienen a que la literatura escrita por ellas pueda circular en igualdad de condiciones que la creada por hombres. Parte de este manifiesto fue publicado por la periodista y escritora Yolanda Reyes en su columna de El Tiempo con el sugerente título de: "En nuestro nombre: ¿Qué significa un país contado en masculino? ¿Qué discursos convencionales se siguen repitiendo?”. El artículo de Reyes reproduce parte de lo que dice el manifiesto de las autoras, así:

Lo insólito, lo que no encaja en esta foto fija, es que en Colombia las mujeres estamos escribiendo, que tomamos muy en serio el oficio, como lo prueban las escritoras de distintas generaciones publicadas por diversos sellos editoriales y en diversos géneros. Que tenemos lectores y editores, dentro y fuera del país, que ganamos reconocimientos y que vivimos de este trabajo. Y que, precisamente, por tratarse de un trabajo -no de un pasatiempo- tenemos las mismas aspiraciones legítimas a participar en los procesos de selección y el derecho a conocer los criterios que se han determinado para integrar las muestras financiadas con dineros públicos. Estamos hablando del derecho (ojo: no es un favorcito) a que nuestras obras sean leídas, conocidas y consideradas en igualdad de condiciones por los comités curatoriales encargados de seleccionar las obras que se llevarán a las muestras, a las ferias del libro y a los encuentros culturales. $(\mathrm{s} / \mathrm{n})$ 
Es importante referir que entre las treinta seis autoras colombianas que firmaron el manifiesto, figuran los nombres de Pilar Quintana y de Melba Escobar. Dos años después, en 2019, año que coincide con la publicación de la novela $L a$ mujer que hablaba sola de Melba Escobar, tuvo lugar otro disenso público de autoras colombianas. En esta ocasión el cartel de escritores invitados como parte de la delegación colombiana a la Feria Internacional del Libro Universitario en Veracruz- México lo conformaban ocho autores, todos hombres. El disenso de las autoras minó nuevamente las redes sociales (posts, hashtag y columnas de opinión) donde volvieron a protestar por la ausencia de una perspectiva de género por parte de las curadurías que eligen los grupos de escritores que representan la literatura colombiana a eventos internacionales (Esquivel s/n). Merece la pena señalar aquí que antes de la publicación de La perra y de La mujer que hablaba sola cada una de las autoras ya habían publicado obras de ficción. Melba Escobar había publicado ya cuatro novelas $(2007,2010,2014,2015)$ entre las cuales se destaca La casa de la Belleza, que fue finalista al premio Nacional de Narrativa Colombiana en 2016 y ha circulado con bastante éxito fuera de país al punto que ha sido traducida a más de doce idiomas. Por su parte, Pilar Quintana había publicado una colección de cuentos $(2012)$ y tres novelas $(2003,2007,2009)$ entre las cuales la más conocida es Coleccionista de polvos raros, que fue galardonada en el 2010 con el premio de La Mar de Letras. Tres años antes, en el 2007, la autora había sido seleccionada en el prestigioso certamen Bogotá 39 entre la lista de escritores menores de 40 años más prometedores de Latinoamérica.

Pese a este historial de cada una de las autoras, los disensos han sido necesarios y han provocado debates en conocidos medios de comunicación como son Revista Arcadia, El Tiempo, El Espectador y Semana, permitiendo en momentos puntuales desestabilizar el criterio "natural" con el que se asume que son hombres escritores los que conforman el panorama actual de la literatura colombiana. El hecho de que la publicación de las novelas, La perra y La mujer que hablaba sola, de Quintana y de Escobar, respectivamente, coincidan ambas con los disensos contra agentes de la institución literaria locales nos lleva a comprender 
que ambas novelas han circulado y han sido recepcionadas, en momentos en que se desestabilizan discursos cómodos y hegemónicos que tradicionalmente excluyen a las escritoras mujeres invisibilizando su trabajo y su voz. En el fondo, lo que está en discusión es el valor que se le asigna al trabajo creativo de las mujeres, ellas recalcan su lugar en la industria literaria en la cual, como dicen en el manifiesto citado más arriba, tienen sus lectores y editores en Colombia como fuera de las fronteras. Con lo cual se entiende que las autoras son conscientes de que sus novelas no tienen una suerte de autonomía al margen de la economía y el mercado y por eso lo que reclaman no es, simplemente, que se les reconozca la labor estética de su creación, sino que sus obras, sean reconocidas como producto de su trabajo y que éste sea valorado (véase Gallego) ${ }^{4}$.

El "desvalor" del trabajo realizado por mujeres, en este caso el de las escritoras colombianas, se puede definir a partir de lo que Silvia Federicci señala como la "división sexual del trabajo", es decir, la clasificación entre hombres y mujeres con su respectiva división de roles. Esta categoría de análisis permite señalar la desigualdad y el desvalor que se asigna al trabajo productivo de las mujeres con respecto al desempeñado por los hombres. Incluso, y como dice Federicci, hay un lazo que une a la contemporaneidad con la historia, pues no es nuevo que la división de funciones según se tratara de mujeres o de hombres, ha permitido que se vea como "no-trabajo" las actividades productivas que desempeñaban las mujeres fuera de casa (141-148). Volviendo a referirnos a las autoras colombianas de nuestra contemporaneidad habría que comprender que su disenso expone cómo la "división sexual del trabajo" las sigue excluyendo de la esfera pública donde, se supone, se debería valorar su trabajo productivo.

Siguiendo nuestra propuesta de análisis y antes de pasar a presentar cómo las ficciones de las autoras Quintana y Escobar construyen disensos, merece la pena presentar algunos rasgos biográficos de cada una de ellas, así como su relación con

${ }^{4}$ Gallego Cuiñas (2014) ha señalado la necesidad de comprender la recepción y circulación de los textos, sin obviar que la literatura se enmarca en las lógicas actuales del mercado capitalista y de la globalización. 
CATEDRAL TomAda: Revista de crítica literaria latinoamericana / Journal of Latin American Literary Criticism Pilar Quintana y Melba Escobar. Disensos y consensos en las novelas La perra (2017) y La mujer que hablaba sola (2019)

el feminismo y su postura política frente al conflicto sociopolítico colombiano. Empecemos por señalar que Pilar Quintana (1972) y Melba Escobar (1976) son contemporáneas y nacidas ambas en la ciudad de Cali. Las autoras pertenecen a la generación que puede dar testimonio de hechos que han marcado la historia finisecular del país como son la violencia de las mafias en los años ochenta, el recrudecimiento del conflicto armado colombiano en los años noventa con la aparición de los paramilitares como parte de los actores armados, la agudización del neoliberalismo y sus políticas de extracción que causaron desplazamientos forzados de poblaciones enteras y al cambio de siglo, el frustrado Acuerdo de Paz entre el gobierno de Pastrana y la Guerrilla de las FARC. Cada una de las escritoras referidas ha expresado su punto de vista con respecto a los nuevos acontecimientos que han marcado el devenir colombiano del siglo XXI entre los que se encuentra la política de Seguridad Democrática durante casi una década, la posterior etapa de moderación de la violencia que permitió la firma del Acuerdo de Paz entre la extinta Guerrilla de las FARC y el gobierno de Santos. Y en la actualidad, el retorno a políticas opresivas y militares que desconocen sistemáticamente el referido Acuerdo de Paz. ${ }^{5}$

En lo que respecta a Melba Escobar, la escritora se ha identificado con lo que llama "extremo centro", expresión a la que acude emotivamente porque la recuerda de su padre, quien fue un político reconocido en Cali. Escobar es columnista del periódico El Tiempo, donde opina sobre diversos temas que ella elige poner en discusión. Uno de ellos fue el de las elecciones presidenciales de 2018 que se disputaron entre la llamada Colombia Humana y, de otro lado, el proyecto de extrema derecha, iniciado por Álvaro Uribe y continuado por Iván Duque, y que ponía en peligro los Acuerdos de Paz. Sin embargo, siguiendo el análisis de la escritora, ambas opciones representaban un peligro para la paz, porque

${ }^{5}$ Desde la firma del Acuerdo de Paz en el año 2016 al mes de junio de 2020 la suma de líderes sociales asesinados era de cuatrocientos cuarenta y dos (442). Asimismo, a julio del 2020 habían asesinado a doscientos veintidós (222) exguerrilleros que se acogieron al Acuerdo de Paz. Este "genocidio", como ya lo llama la analista y politóloga Sara Tufano (2020) se asemeja a lo ocurrido con la UP (Unión Patriótica) durante las décadas de los ochenta y noventa. 
"cada uno de ellos [Petro y Duque] representa una provocación para un sector del país" (Carta blanca al futuro $\mathrm{s} / \mathrm{n}$ ). La postura política de la escritora parte de identificar en la política colombiana una polarización de extremos de la cual ella quisiera apartarse. No obstante, es precisamente esa dualidad la que está presente en su escritura, tanto en la periodística como en la novela que nos ocupa. En lo que atañe a La mujer que hablaba sola, desde ya hay que señalar que en su construcción narrativa persiste una indagación sobre cómo los extremos ideológicos, de un lado, de izquierda y, de otro, de derecha, en el contexto urbano bogotano, actúan como fuerzas que forjan el destino de los personajes.

En lo que respecta a Pilar Quintana, la autora no tiene una tribuna periódica desde la cual expresarse. Sin embargo, después de haber sido seleccionada en la lista de Bogotá 39 en el año 2007 la autora ha contado con una apertura de espacios en los que ha expresado su opinión y postura frente a la realidad del país. En el 2018, en vísperas de las elecciones que definirían el destino del Acuerdo de Paz, Quintana decía en una entrevista que concedió al diario español El Pais, que había en Colombia una polarización entre "dos bandos encabezados por Petro y por Duque" (Torrado s/n). Sin embargo, a diferencia de la escritora Melba Escobar la postura de Quintana no consistía en la necesidad de ubicarse en el centro, sino de comprender el teatro político en las elecciones colombianas. Su perspectiva era claramente la de apoyar la paz, pero Quintana optaba por la periferia, no le interesaba buscar un centro entre discursos opuestos sino más bien tener una perspectiva desde los márgenes.

Esa perspectiva marginal y periférica de Pilar Quintana es también la que se encuentra en su novela La perra, la cual indaga la violencia instintiva que habita en Damaris, la protagonista, y que aflora poco a poco a medida que avanza el relato. La construcción narrativa de esta novela está ligada al espacio marginal que es el pacífico colombiano. En un nivel, este lugar es medular y nada transponible a otras realidades, pues la peculiar combinación de selva, mar y el clima ecuatorial es casi un protagonista más en la historia y está vinculado al modo de ser, de pensar y de 
CATEDRAL TomAda: Revista de crítica literaria latinoamericana / Journal of Latin American Literary Criticism Pilar Quintana y Melba Escobar. Disensos y consensos en las novelas La perra (2017) y La mujer que hablaba sola (2019)

vivir de la protagonista, incluso, algunas veces, el húmedo trópico es un anunciador de su destino.

De modo que hay una diferencia de miradas en la construcción narrativa de cada una de las novelas. Mientras que en La mujer que hablaba sola el relato ocurre en un lugar central de Colombia, Bogotá, en La perra todo sucede en un espacio aislado y abandonado del pacífico colombiano. Asimismo, mientras que en la novela de Escobar hay "espacios ideológicos", por llamar así a esa dimensión conflictiva en la cual los extremos de izquierda y de derecha coartan el destino de los personajes y ubican al lector en la realidad colombiana del posconflicto, en $\mathrm{La}$ perra, la dimensión conflictiva y de violencia parece connatural al territorio y a sus habitantes.

Ahora bien, tanto Pilar Quintana como Melba Escobar se definen feministas, ninguna de las dos es militante, pero a ninguna de ellas le incomoda identificarse como tal. La primera se acercó al feminismo bastante tarde, después de terapias y de lecturas que le ayudaron a comprender que su exmarido era un maltratador y que ella hizo bien en huir de casa para mantenerse viva. De otra parte, Melba Escobar tiene su propia opinión del feminismo, para ella este "debe ser plural" que "no haya un rótulo que nos encasille o un corsé que pretenda condicionar nuestros movimientos" (Arévalo s/p). Ambas, desde su lugar de escritoras, se han preocupado por explorar en su escritura de ficción temas que siempre han sido tratados en la literatura como son el poder, el amor, el deseo, incluso, el narcotráfico. Todo ello, como lo hemos señalado más arriba, sin ignorar la óptica de personajes femeninos.

Con anterioridad a las novelas que abordamos en este artículo cada una de las autoras ya habían trabajado en su ficción la presencia de personajes femeninos permeados, tal como en la sociedad colombiana, por las divisiones de clase. Así, en Coleccionista de polvos raros (2007), Quintana literaturizó parte de la historia del narcotráfico en la ciudad de Cali a finales de los años ochenta y noventa poniendo en su centro la vida de una joven que poco a poco nos desvela su forma de vida en un contexto patriarcal y corrupto. Por su parte, Melba Escobar en su libro La casa 
de la belleza (2010) sitúo a sus protagonistas en Bogotá y valiéndose de múltiples narradoras hizo literatura del narcotráfico indagando el rol de la mujer en una sociedad donde es vista como una mercancía más. En las novelas cada una de las autoras ya había elegido romper con relatos tradicionales de la literatura en los cuales las mujeres son descritas desde afuera y no saben qué les pasa en su alma ni cuáles son sus deseos.

Llama, sin embargo, la atención que no haya una mirada feminista acerca de las dificultades de las autoras al aupar el oficio de ser escritora con la de ser madre. Escobar tuvo su hijo y dejó de escribir periódicamente en su columna de $E l$ Tiempo, es de suponer que también interrumpió su tiempo de creación literaria o en todo caso que menguó esta producción. Es más conocido el hecho de que La perra fue escrita por su autora mientras que su bebé hacía la siesta en el canto y estaba siendo amamantado. En esos momentos de tranquilidad del niño la madre aprovechaba para escribir en un bloc de notas de su teléfono celular la historia que tenía en mente y que con el tiempo pudo llegar a ordenar y retrabajar ante una pantalla de su ordenador para finalmente, dar la forma a la novela corta que fue titulada La perra. La manera anecdótica en que se ha tratado el proceso de escritura de Quintana debería cuestionarnos acerca del reparto del espacio, de los cuerpos y del tiempo en el orden de lo sensible. Rancière ha teorizado sobre la división de los cuerpos y su correspondiente saturación del "espacio y del tiempo", se trata de una partición desigual en la que hay unos "destinados" a trabajar mientras otros a pensar o a filosofar (134). El teórico se remonta a la filosofía griega para aterrizar su reflexión en el mundo contemporáneo y señalar que, desde la antigua Grecia hasta hoy, buena parte de la población ha sido excluida del ejercicio de la ciudadanía, del arte y la política porque su tiempo ha sido destinado para lo que él llama "el trabajo de brazos" (95-8).

El filósofo francés, sin embargo, tampoco está pensando en la maternidad, ni en la partición desigual del espacio y del tiempo por razón de género, ni en la consecuente sobrecarga que tienen las mujeres por su trabajo de crianza, hogar y labores productivas. Por eso resulta más esclarecedor volver al feminismo y al 
CATEDRAL TomAda: Revista de crítica literaria latinoamericana / Journal of Latin American Literary Criticism Pilar Quintana y Melba Escobar. Disensos y consensos en las novelas La perra (2017) y La mujer que hablaba sola (2019)

concepto de "división sexual del trabajo" de Federicci para comprender la relación entre el capitalismo y el desequilibrio de tiempo, espacio y trabajo por razones de género. La italiana señala la necesidad de repensar nuestra sociedad en términos feministas, ya que el sistema capitalista y ultraliberal obvia todo aquello que necesitamos para la reproducción de la vida y su sostenimiento o lo que llamamos "cuidados".

Separando las esferas pública y privada se ordenan funciones a cada una de ellas, a la primera, se le asigna la función del trabajo productivo (valorado económicamente) y, a la segunda, la reproductiva a la cual fueron desplazadas las mujeres y que ha sido excluida de valor. Y aquí merece la pena volver a nuestras escritoras, concretamente a ese trabajo reproductivo que es la crianza y el productivo de la creación literaria. Usando los términos de Federicci hay una "plusvalía” que generan las mujeres en su trabajo de "cuidados” y que lo apropia el capitalismo (141-148). Esta situación debería ser un disenso más para incluir al debate de la literatura escrita por mujeres, pues si ya la labor de la escritura está devaluada en esta sociedad, las mujeres por el hecho de la maternidad están expuestas a abandonar su trabajo de creación literaria para atender su vida reproductiva o en otros casos a reprimir una maternidad deseada para poder cuidar su productividad.

Concluyendo con la reflexión expuesta y en vía de pasar a presentar cómo se teje la estética de las novelas La mujer que hablaba sola, de Melba Escobar y La perra, de Pilar Quintana, nos disponemos a presentar respuestas a las siguientes preguntas: ¿qué disensos y consensos son identificables en la construcción narrativa en cada una de las novelas referidas?, ¿cómo se articula en cada una de las novelas el puente entre violencia y la vida íntima de las protagonistas?, ¿qué visión éticopolítica resulta de la propuesta estética de cada una de las novelas en lo referente a la violencia y al papel de las mujeres protagonistas? 


\section{La mujer que hablaba sola ${ }^{6}$ : intimidad y conflicto social}

La novela de Melba Escobar, La mujer que hablaba sola, recurre a una narradora en primera persona que excava en los recovecos de la memoria. El uso de esa primera persona y el tono de confidencia implican afectivamente al lector que zigzaguea en un ir y venir: por momentos vinculado con ese mundo interior de la narradora y en otros momentos algo desconectado de su perspectiva. Y es que podríamos lanzarnos a asegurar que hay una identificación bastante compleja de la autora que, en su búsqueda por dar su opinión con respecto a acontecimientos contemporáneos de la realidad colombiana y más específicamente bogotana, se desdobla algunas veces en la narración y expone sus propios puntos de vista.

En esta novela, el modo de movilizar el relato se da porque Cecilia, la narradora, que es madre de Pedro y viuda de Rayo, en una especie de epístola hablada hace un recuento de su vida. La voz de Cecilia es prevalente, viajando por el tiempo es la voz de una mujer que en el presente tiene un poco más de cuarenta años y salta en el tiempo veinte años atrás. Cecilia se dirige a Rayo, su marido ya muerto. Es a él a quien le cuenta su presente y le habla del pasado: "El caso es que Pedro, nuestro hijo, no está. No sé si vuelva a verlo. No sé si es culpable o no. Estamos en el año dos mil diecinueve, pero en mi cabeza vuelvo una y otra vez sobre la noche de nuestra boda hace casi veinte años" (13).

La ausencia de Pedro, el hijo adolescente, es la que ha motivado la narración de Cecilia. También es él la figura que funciona en el relato para articular el mundo interior de la mujer con el mundo exterior de la ciudad de Bogotá, lugar donde se desarrolla principalmente la acción. Asimismo, se distingue en la ficción la inclusión de un acontecimiento histórico violento que marcó a esta ciudad en el año 2017 cuando explotó una bomba en el Centro Comercial Andino. Sin embargo, este suceso tiene en la novela una función específica. No está allí en la narración porque interese reescribir ese hecho histórico con el fin de que no pase al olvido, sino más bien para reforzar el planteamiento de la novela acerca de que la vida de las mujeres

\footnotetext{
${ }^{6}$ Todas las citas a la novela corresponden a La mujer que hablaba sola. Bogotá: Planeta, 2019.
} 
CATEDRAL TomAda: Revista de crítica literaria latinoamericana / Journal of Latin American Literary Criticism Pilar Quintana y Melba Escobar. Disensos y consensos en las novelas La perra (2017) y La mujer que hablaba sola (2019)

y los hombres de la sociedad narrada están limitados en sus comportamientos e ideas por causa de un ambiente social impregnado de violencia y hostilidad.

Ciertamente, el discurso que dirige Cecilia a Rayo lo motiva la persecución que la policía ha emprendido contra Pedro. Ella sabe que su hijo partícipe o no de la bomba que se detonó en el centro comercial ya está señalado como culpable, pues en la sociedad en la que viven se criminaliza sin mediar juicios. Incluso, su hijo está incriminado y señalado desde altas esferas de poder:

Regresé para ver imágenes de cuatro de los Once Apóstoles y capturados, casi todos de capucha, cubriéndose torpemente mientras la cámara se esforzaba por descubrir sus rostros [...] Mostraron una vez más, la foto de Pedro con un letrero en generador de caracteres en el que se leía: "alias Pedro”. ¿Alias Pedro? Su nombre es ese. ¿Alias Pedro? ¡El nombre de mi hijo no es un alias! [...] El ministro Villamizar disfrutaba su cuarto de hora televisivo: "Tenemos información veraz de que esos bandidos son del MRC, la célula urbana del ELN. A esta hora tenemos tres prófugos que esperamos sean capturados las próximas horas”. (106)

En la cita referida los medios de comunicación hablan de "bandidos" de una "célula urbana del ELN" y de los "Once apóstoles", los cuales se ubican ideológicamente a la extrema izquierda. Ellos son ese "otro" que no es contado en un llamado "nosotros". Esta división merece la pena pensarla en los términos de Rancière cuando dice que en la repartición desigual de lo sensible hay una "distribución de los cuerpos que los mantiene a distancia a los unos de otros, dejado exclusivamente a los "mejores" el espacio central de lo político" (99). La referencia al filósofo es apropiada para comprender el sentido de la narración que nos presenta esos escenarios donde hay una división de cuerpos, de espacios y de ideología.

El hijo de Cecilia, Pedro, funciona también en la narración como puente o bisagra para articular el encuentro o (desencuentro) entre ese mundo social bogotano dividido por clase e ideología. Ya que él perteneciendo a una familia 
burguesa se identifica con los "otros" o con los que están al otro lado de donde él vive. Así lo recuerda su madre:

Mi Pedro pasará otro domingo tomando cerveza en una calle sin pavimento. Se burlaría sin duda de mi descripción burguesa de un barrio popular. Le parecería un cliché, tendría razón. Ya sabes que nunca he estado en Soacha. Tampoco en Kennedy, ni en Bosa, ni en Ciudad Bolívar, ni en Usme $[\ldots]$ ¿Tengo que darme golpes de pecho por eso? Pedro diría "pero si estás a tiempo de cambiar". (77)

Así expone Cecilia que su hijo es todo lo que ella no es, él conoce la Bogotá que ella no conoce, incluso, se identifica con una ideología que para ella ha quedado atrás. En las conversaciones que tenía con su hijo queda claro que él tenía una visión romántica de las guerrillas, él se identificaba como un "soldado de la paz" mientras ella le decía: "lo veo como desfasado, comandante, porque la paz ya la firmó Santos con las FARC [...]" (26). Este tipo de frases, que expresan la distancia entre madre e hijo y que se encuentran a lo largo de la narración lleva a plantearnos la pregunta de: ¿por qué la narración se interesa por recrear un permanente desencuentro entre madre e hijo? En nuestra opinión, la elección de la autora de decantarse por una narradora como Cecilia -mujer de familia burguesa bogotana- para ser madre de Pedro, resulta una elección estética que acompaña una postura ético-política de ese sentimiento que Nussbaum (2008) llama la "compasión" o la necesidad de ponerse en el lugar del otro y de entender otra visión. Especialmente, vemos los desdoblamientos que muchas veces tiene la autora en la narradora como una búsqueda de identificación de la propia Melba Escobar con la angustia de una madre, como las hay muchas en Colombia, que tiene a su hijo perseguido en el contexto del conflicto sociopolítico.

Otra propuesta más de la narración consiste en asegurarle al lector que el conflicto político y social es localizable en la ciudad, incluso, que se vive al interior del hogar. Esta visión, aunque parezca lógica en un país que ha experimentado más 
CATEDRAL TomAda: Revista de crítica literaria latinoamericana / Journal of Latin American Literary Criticism Pilar Quintana y Melba Escobar. Disensos y consensos en las novelas La perra (2017) y La mujer que hablaba sola (2019)

de cincuenta años de conflicto armado, refuta la idea generalizada por los bogotanos de que la guerra no se vive en la ciudad. Y aquí hay que señalar que el tono íntimo que Cecilia utiliza para hablarle a Rayo sobre el pasado que compartieron juntos, es el mismo que utiliza para referirse a la ideología de izquierda, a la guerrilla y a la situación en la que está su hijo. De modo que en esa "epístola hablada" en tono íntimo que la narradora dirige a su marido ausente ocupa tiempo y espacio la temática del conflicto social. Así, el lector acompañando a la narradora llega a sentir que el conflicto no pertenece a lo exterior, sino que lo desborda. En este sentido la narración de La mujer que hablaba sola opera un disenso. Lo cual es lo mismo que decir que esta poética aporta una visión ético-política que repercute en la interpretación del "mundo sensible" del contexto colombiano.

Ahora bien, ocurre que la ficcionalización del acontecimiento histórico violento que marcó la ciudad de Bogotá en el año 2017 ha provocado una particular forma de recepción de la obra de parte del público lector. Por lo reciente que estaban los acontecimientos para la época de la publicación de la obra y por lo actual que resulta la necesidad de negociar la memoria del conflicto colombiano, la novela ha tenido la particularidad de vincular fuertemente la experiencia de lectores con la necesidad de acordar una memoria colectiva de ese hecho. Siguiendo al hispanista Hansen Lauge (2012) ${ }^{7}$ en sociedades con una necesidad de negociar la memoria juegan un papel fundamental las narraciones marcadas de discursos híbridos. La imbricación de discurso historiográfico y discurso ficticio interpela a los lectores que se sienten llamados a participar en una realidad imaginada de manera que el lector mismo se implica como testigo en la búsqueda y consecución de la verdad. Esta explicación acerca de la implicación del lector y su necesidad de consecución de una verdad funciona para explicar la desaprobación que ha tenido el libro, especialmente, en círculos de estudiantes. Ocurre que jóvenes que pertenecen a la misma generación de Pedro (que en la novela está en sus veinte años) han sido

\footnotetext{
${ }^{7}$ Aunque el hispanista se refiere a la negociación de la memoria de la Guerra Civil en el contexto español, su teoría es acoplable a las formas narrativas de La mujer que hablaba sola de Melba Escobar.
} 
señalados por las autoridades colombianas de estar vinculados con el atentado del Centro Comercial Andino. La negociación de la memoria de ese hecho violento está inconclusa y está abierta la necesidad de una justicia y verdad tanto para las víctimas del atentado como para las víctimas del aparato judicial. ${ }^{8}$

En nuestra opinión la novela incluye el acontecimiento violento de lo ocurrido en el centro comercial sin la intención de dar una versión de lo que allí sucedió, sino como propuesta para que el lector se sitúe frente a un hecho y se desplace del lugar cómodo o fácil que puede encontrar entre alguno de los binarios de izquierda y derecha. Esta propuesta, sin embargo, no es neutra, sino que parte de identificar en la política colombiana una polarización de extremos de la cual la narradora quisiera apartarse a un centro. No obstante, es precisamente entre ese pensamiento binario en el que se quedan atrapados los personajes y el lector. En este sentido la narración no disiente o no altera la repartición de lo sensible, por el contrario, prolonga la idea de la rigidez de los discursos, por ejemplo, el de la izquierda, que se presenta vacío y sin vigencia. Pasando por alto la complejidad del conflicto social y político de la nación en donde persiste, aún después de los Acuerdos de Paz, la eliminación física de aquel que vaya en contra del poder hegemónico.

Así, de polo a polo la narración persiste en una indagación sobre cómo los extremos ideológicos en el contexto urbano bogotano actúan como fuerzas que forjan el destino de los personajes. Sin embargo, aquí el destino ya no es el fatum de tragedia antigua, del discurso profético cuya ley es prescriptiva y define el devenir de los hombres sujetos a las leyes, sino el destino al que Sultana Wahnón (2003) refiere como el daimon o carácter inquietante de la especie humana que a diferencia de lo trágico antiguo no consiste en un destino fatídico e ineludible sino,

\footnotetext{
${ }^{8}$ El atentado en el Centro Comercial Andino ocurrió justo antes de que la Guerrilla de las FARC terminara la total entrega de armas. Esta guerrilla rechazó el atentado y negó su autoría. Tal como ocurre en la novela, en los medios de comunicación se ha señalado que en los hechos participaron unos jóvenes vinculados a la guerrilla del ELN. Otra versión ha circulado entre la ciudadanía y es la del atentado como montaje de parte de fuerzas que han estado en desacuerdo desde el principio con el Acuerdo de Paz firmado entre las FARC y el gobierno de Santos.
} 
CATEDRAL TomAda: Revista de crítica literaria latinoamericana / Journal of Latin American Literary Criticism Pilar Quintana y Melba Escobar. Disensos y consensos en las novelas La perra (2017) y La mujer que hablaba sola (2019)

como ocurre en efecto en la novela mencionada, un destino asociado con un terror político (225).

\section{La perra ${ }^{9}$. Maternidades y violencia}

A diferencia de la fícción de Melba Escobar que incluye un hecho histórico de la realidad nacional ubicando al lector en un contexto social politizado, en la ficción de La Perra, de la escritora Pilar Quintana, no hay en los acontecimientos materia de diégesis referencias directas al acontecer del conflicto político colombiano. Sin embargo, de acuerdo con Leonardo-Loayza (2020) la historia puede interpelarnos acerca de la violencia en el posconflicto, en palabras del peruano: "[...] pareciese que la novela habla sobre el posconflicto que vive Colombia, sobre su periodo de paz, y advirtiera que no obstante la violencia a gran escala está desapareciendo, la de escala menor, doméstica, microfísica, aún sigue en pie, instalada en el interior de la gente" (166).

En efecto, el discurso literario de La perra toma sentido porque está dirigido al lector contemporáneo que asume la historia desde un lugar muy diferente al periférico donde vive Damaris -la protagonista del relato-. Pues si nos compadecemos de ella, es porque sabemos que en una sociedad interconectada como la actual Damaris no debería experimentar el abandono y aislamiento al que está destinada. Tampoco aceptamos la presión y el sufrimiento que la protagonista se autoinflige por su incapacidad de tener hijos, porque juzgamos esa realidad desde un presente en el que ese conflicto podría ser resuelto con tratamientos de fertilidad por la ciencia médica.

Así, despojada la narración de nombres, fechas, hechos históricos del conflicto colombiano sin literaturizar, la dimensión ideológica de la lengua en la novela de Pilar Quintana sobreviene porque está dirigida a cuestionar el destino de una mujer contemporánea, a quién le tocó nacer y forjar su vida en un lugar de la costa caucana del pacífico colombiano. La decisión estética de literaturizar parte del pacífico, territorio que ha sido caracterizado según Gonzalo Sánchez (2015) por

\footnotetext{
9 Todas las citas corresponden a La perra Bogotá: Random House, 2017.
} 
vivir "una catástrofe humanitaria de larga duración", es sin lugar a dudas una determinación ético-política de la autora que busca confrontar al lector con la incomodidad de un lugar como lo es la costa del pacífico colombiano.

Quintana acude a una voz narrativa externa en tercera persona y algunas veces esta voz se interrumpe con la propia voz de Damaris, que es la protagonista de la novela y la mujer que está en el centro de la narración. A diferencia de La mujer que hablaba sola, donde hay una identificación compleja de la autora con respecto a la narradora, en La perra no ocurre lo mismo ya que la voz narrativa posee gran autonomía frente a la autora, quien eligió poner en el centro de la narración a Damaris, una mujer negra, ancha y pesada. Es el personaje arquetipo que Virginia Despentes (2007) llama "figura perdedora de la feminidad" (8), y que a la francesa le resulta tan simpático ya que va a la contra de heroínas contemporáneas de la literatura tan aptas para querer a los hombres o hacerse querer por ellos. Ciertamente, Damaris está en conflicto con su feminidad por la imposibilidad de quedar embarazada y de responder a esas preguntas que le lanzaba la gente: “¿Para cuándo los bebés? o "Qui' hubo que se están demorando" (19). La imposibilidad de ser madre le provoca un extrañamiento de su propio cuerpo: “[...]Damaris se estuvo mirando las manos durante un rato. Las tenía inmensas, con los dedos anchos, las palmas curtidas y resecas y las líneas tan marcadas como grietas en la tierra. Eran manos de hombre, las manos de un obrero de construcción o un pescador capaz de jalar pescados gigantes" (59).

Mirada desde la perspectiva que rescata Despentes, la figura de Damaris resulta simpática, fundamentalmente, porque es una mujer deseante, que conoce su más íntimo deseo y lo expresa. Ella quiere tener un hijo y se lo dice a Rogelio, su esposo, el día en que él le comenta que irá al puerto de Buenaventura a comprar un equipo de sonido: "-Yo no quiero un equipo de sonido -le dijo- yo quiero un bebé" (22). La voz de Damaris en primera persona reemplaza la voz narradora en tercera persona que la mayor parte del tiempo cuenta la historia. De este modo la autora permite que Damaris asiente o niegue sus propios deseos y también que el personaje tenga su propia identidad. El resultado es una protagonista de personalidad fuerte 
CATEDRAL TomAda: Revista de crítica literaria latinoamericana / Journal of Latin American Literary Criticism Pilar Quintana y Melba Escobar. Disensos y consensos en las novelas La perra (2017) y La mujer que hablaba sola (2019)

como su cuerpo, pero también vulnerable e inesperada como es el territorio de pacífico y el clima tropical.

Sea este el momento de señalar que a contrapelo de La mujer que hablaba sola, donde la protagonista es mestiza y de familia burguesa, en La perra la figura principal es de raza negra y pobre. La edad de Damaris ronda los cuarenta años, tiempo en que "las mujeres se secan" (25), como se lo había oído decir a su tío y a tanta gente de la zona. En la novela de Escobar, la protagonista, Cecilia, está también en sus cuarenta años de edad. Ambas novelas literaturizan la maternidad en toda su complejidad. En ninguna de las dos ficciones las mujeres viven la maternidad de la forma delicada, plácida y bella como la ha narrado Gioconda Belli en unos de sus poemas:

Por las noches ya me despiertas

con tu suave golpeteo

a las puertas de mi casa más secreta.

Platicamos sin palabras

Y luego te arrullo

con el corre de mi sangre

y los latidos de mi corazón. ("Feto" 3-4)

En el caso de Damaris, la sensación más cercana que experimentó a la maternal de llevar un hijo en su vientre fue en los momentos en que cargaba a su cachorrita entre el pecho, dice la narradora: "Damaris llevaba a la perra metida en el brasier, entre sus tetas blandas y generosas para mantenerla calientica" (16). Y en el caso de Cecilia la experiencia de su embarazo, aunque fue una recompensa por ese hijo que en un pasado abortó, significó un enclaustramiento en un estilo de vida en el que no pudo cumplir sus deseos. Damaris deseaba la experiencia de una maternidad que nunca llegó a vivir y Cecilia deseaba la libertad: otro país, otro hombre, otro trabajo. Y posiblemente, otro hijo diferente al que tuvo. 
Cada una de las novelas nos descubre unas emociones perturbadoras en donde se ficcionaliza la maternidad de forma íntima, sin idealizaciones y sin obviar el proceso de gestación. Fracasada en el caso de Damaris y, en el caso de Cecilia, impuesta por la inercia de la cultura en la cual creció. Tanto Quintana como Escobar se interesaron por ahondar en ese proceso femenino presentándolo desde una óptica introspectiva y en su desgarradora materialidad. Ni Cecilia ni Damaris afianzan una idea de identidad entre mujer y naturaleza, por el contrario, el planteamiento de cada una de las novelas en lo que atañe a la maternidad coincide con la idea de Butler que invita a concebir el cuerpo como posibilidad histórica que aloja prácticas pasadas, presentes y futuras (299).

En nuestro concepto, este tratamiento estético de la maternidad en ambas ficciones plantea una ética del disenso. Desde ópticas muy distintas las ficciones de Quintana y de Melba Escobar plantean la posibilidad de una reconfiguración del cuerpo y de la concepción de la maternidad. En el planteamiento de La perra, Damaris tendría que aprender a resignificar su cuerpo con otra posibilidad diferente a la maternidad y en la propuesta de la ficción de La mujer que hablaba sola, Cecilia podría darle un nuevo sentido a la experiencia pasada, tal como lo hace en la narración, a través del lenguaje y la rememoración.

Ahora bien, volviendo a la ficción de La perra surge una pregunta acerca del tratamiento de la violencia, elemento que da estructura a toda la narración. El libro abre en su primera página con la figura de una Damaris desprevenida y anonadada de que en el pueblo los perros mueran envenenados y cierra también con ella, esta vez con una Damaris huidiza que evita a toda costa la llegada de los gallinazos sobre los restos de la perra que ella acaba de matar. La escena es de una violencia brutal y mezcla otra violencia que no ha sido narrada pero que está en la mente de Damaris, seguramente porque supo de ella o la vio. Sucede tras haber matado a la perra, cuando Damaris se mira al espejo y cree ver a otra mujer, a una que picó a su marido: "Quería ver si se encontraba en ese espejo la mirada de la mujer que había picado al marido y le pareció que sí y que la gente la reconocería y se daría cuenta de lo que había hecho" (107). 
CATEDRAL TomAda: Revista de crítica literaria latinoamericana / Journal of Latin American Literary Criticism Pilar Quintana y Melba Escobar. Disensos y consensos en las novelas La perra (2017) y La mujer que hablaba sola (2019)

$\mathrm{Y}$ es que a lo largo de la novela se nos presentan imágenes de hechos violentos que solamente se señalan pero que no se desarrollan narrativamente quedando sueltos y sin explicación. El lector queda preguntándose, por ejemplo: ¿qué pasa con las muertes de algunos personajes como la del hombre que cuida la casa de los Reyes y que resulta ahogado en el mar? o ¿por qué la bala perdida que causa la muerte de la madre de Damaris? Al respecto, estamos de acuerdo con Loayza en su observación acerca de que hay en la novela un silenciamiento de varias manifestaciones de violencia y que estas se aceptan como parte de la cotidianidad: "Es como si, a pesar de que existen estas manifestaciones de violencia, se prefiriera silenciarlas, negarlas. Solo ocurren y ya. A nadie (incluyendo al narrador) le interesa saber ni decir más de la cuenta, se las acepta como un hecho más de la cotidianidad" (166).

En nuestra opinión esta estética del silenciamiento de la violencia se puede explicar por algunas razones. La primera es práctica, La perra estaba pensada en principio para ser un cuento largo, sin embargo, como recuerda Quintana, resultaron más páginas de las pensadas, así que ella y su editora decidieron darle la forma de lo que llegó a ser: una novela corta con una historia muy concreta que sería sobre la maternidad y una perra (Diario de Paz). La segunda, es una razón más aventurada y es que Quintana decidió que, incluso en el relato de un cuento, no era necesario profundizar sobre la violencia, por la complejidad y la atrocidad que la caracteriza en la zona costera del pacífico que es el territorio ficcionalizado en la novela.

Ocurre que años antes de la publicación de la novela, en el 2013 y en el 2015, el Centro de Memoria Histórica publicó el conocido informe ¡Basta Ya! Colombia: memorias de guerra y dignidad y otro titulado Buenaventura: un puerto sin comunidad, respectivamente. Estas narrativas sobre la memoria de la guerra visibilizaron que la región del pacífico es la que más acumula en cifras víctimas del conflicto armado, entre otras cosas, porque conjuga violencias raciales y territoriales con procesos de industrialización. En esa zona vive el mayor porcentaje de la población afrodescendiente de Colombia y es allí donde se encuentra el puerto 
más importante del país, sin embargo, la población negra no tiene los servicios básicos como el agua o la luz y es la población que ha sufrido de forma particular la violencia del despojo.

En todo este entramado de violencia, como lo consigna el informe de Buenaventura: un puerto sin comunidad hay un ensañamiento particular con el cuerpo de las mujeres, que en la mayoría de los casos se utiliza para enviar mensajes de retaliación o advertencia. Esta violencia contra las mujeres ha sido interpretada como una manera de aniquilar el colectivo o la identidad de la población afrodescendiente donde las mujeres son las transmisoras de la memoria y de las prácticas ancestrales de la población. Por esta razón el daño a las mujeres contiene una carga simbólica relacionada con la intención expresa de aniquilar también al colectivo y la identidad que lo soporta (290-5).

Este panorama de memoria de atrocidades de la violencia actualiza para el caso colombiano lo que Gabriel Gatti (2006) llama la quiebra del lenguaje y la dificultad de representar la experiencia. ${ }^{10}$ Idea que también expresó Adorno después de Auschwitz, cuando se preguntó sobre el lugar de la escritura tras la experiencia límite. Cuestionamiento que en nuestra opinión se actualiza en sociedades que emprenden procesos de construcción de la memoria para comprender experiencias de violencias estructurales. Dicho esto, y volviendo a lo que llamamos la estética de silenciamiento de la violencia que identificamos en la novela de Quintana, es evidente que La perra no es una narrativa que pretenda hacer ficción de la memoria, ni tampoco le interesa plantear una reflexión acerca de ella pese a que es una columna vertebral de la narración.

A diferencia de La mujer que hablaba sola en donde la narración construye un puente o un punto de bisagra entre la violencia social y la vida íntima de la protagonista, en La perra la violencia social existe, pero se silencia o se mimetiza en la selva, incluso, en el mar. Esta estética hace pensar en la rutinización del conflicto en la zona del pacífico. En este sentido, advertimos que la narración no

${ }^{10}$ Aunque Gatti tiene en mente las desapariciones ocurridas en el Cono Sur sus reflexiones son válidas para pensar la relación entre escritura y violencia en el contexto colombiano. 
plantea un disenso, ya que no propone una ruptura o nueva mirada sobre ese orden rutinario con el que se concibe la violencia en una zona tan conflictiva. El silencio sobre la violencia, sin embargo, no lleva a pensar en otro territorio diferente a ese pacífico que aúna una poderosa selva parecida a la amazónica pero con playas tropicales, paisaje que la autora y, evidentemente, la protagonista de la novela conoce a la perfección.

Para concluir quisiéramos apuntar que lejos de buscar en la ficción una representación de la realidad, lo que hemos hecho es un intento por identificar en las ficciones giros, escalas o formas de enunciación para comprender la propuesta ético-política en cada una de las novelas. Los disensos y consensos identificados pueden a su vez servir como reflexión acerca de las posibilidades o dificultades del lenguaje para discernir problemáticas sociales en las cuales enfocamos la mirada femenina. Esto no quiere decir que por el hecho de leer a mujeres autoras sus textos impriman esa mirada. Pues no comprendemos los textos en una concepción naturalista pensándolos como vehículo expresivo de contenidos vivenciales, como si el texto fuera la extensión del género sexual de las autoras (Richard 24-5). Por el contrario, hemos analizado cómo las narraciones entablan algunas veces una dialéctica de la continuidad y otras veces crean rupturas. Lo cual quiere decir que los textos de las autoras no desestabilizan per se discursos patriarcales, sino que debe haber un voluntarioso trabajo de transformación. 


\section{Bibliografía}

Alzate, Carolina. Soledad Acosta de Samper y el discurso letrado de género, 1853-1881. Madrid/Frunkfurt: Iberoamericana, 2015.

Arévalo Domínguez, Laura. "Melba Escobar: las mujeres no somos una franquicia" El Espectador, 2 de abril de 2019.

https://www.elespectador.com/noticias/cultura/melba-escobar-lasmujeres-no-somos-una-franquicia/ Octubre 30 de 2020.

Belli, Gioconda. "Feto", El ojo de la mujer. Madrid: Catedra, 2015 [1992]

Butler, Judith y Marie Lourties. "Actos performativos y constitución del género: un ensayo sobre fenomenología y teoría feminista." Debate feminista, vol. 18, 1998, pp. 296-314.

Capote Díaz, Virginia. Reescribir la violencia: Narrativas de la memoria en la literatura femenina colombiana contemporánea. Bruselas: Peter Lang, 2016.

CNMH. Centro Nacional de Memoria Histórica. Buenaventura: un puerto sin comunidad. Bogotá: CNMH. 2015.

http://www.centrodememoriahistorica.gov.co/descargas/informes2015/b uenaventuraPuebloSinComunidad/buenaventura-un-puerto-sincomunidad.pdf

Despentes, Virginie y Preciado, Beatriz. Teoría King Kong. Barcelona: Melusina, 2007.

Diario de Paz Colombia. Pilar Quintana visita nuestro club. Youtube, s/f. https://www.youtube.com/watch?v=dDimRUQ2jBw Octubre $30 \mathrm{de}$ 2020.

Escobar, Melba. La mujer que hablaba sola. Bogotá: Planeta, 2019. . "Carta blanca a futuro. Votaré, por una Colombia donde quepamos todos, estemos o no de acuerdo." El Tiempo, 16 de junio de 2018. https://www.eltiempo.com/opinion/columnistas/melba-escobar/cartablanca-al-futuro-voto-en-blanco-melba-escobar-231264 Octubre 30 de 2020

Español Casallas, Janneth. Literatura y derecho. Los usos de la memoria en Rafael Chirbes y Laura Restrepo. Tesis Universidad de Granada, 2019. https://digibug.ugr.es/bitstream/handle/10481/56208/57072.pdf?sequenc $\mathrm{e}=3$ \&isAllowed $=\mathrm{y}$

Gallego Cuiñas, Ana. "El valor del objeto literario". Ínsula vol. 814, 2014, pp. 25.

Gatti, Gabriel. "Las narrativas del detenido-desaparecido (o de los problemas de la representación ante las catástrofes sociales)". CONfines de Relaciones Internacionales y Ciencia Politica vol.2, no 4, 2006, pp. 27-38.

Hansen Lauge, Hans. "Literatura y memoria cultural en España (2000-2010)". La memoria novelada. Hibridación de géneros y metaficción en la novela española sobre la guerra civil y el franquismo (2000-2010). Hans 
CATEDRAL TomAda: Revista de crítica literaria latinoamericana / Journal of Latin American Literary Criticism

Pilar Quintana y Melba Escobar. Disensos y consensos en las novelas La perra (2017) y La mujer que hablaba sola (2019)

Hansen Lauge y Juan Carlos Cruz Suárez (Comp.). Bern: Peter Lang, 2012, pp. 21-41.

Jaramillo, María Mercedes, et al. Meira del Mar: Poesía y prosa. Barranquilla: Universidad del Norte, 2006.

Nussbaum, Martha. Paisajes del pensamiento. La inteligencia de las emociones. Barcelona: Paidos Ibérica, 2008.

Ortiz, Lucía. "Narrativa testimonial en Colombia: Alfredo Molano, Alonso Salazar, Sandra Afanador". Literatura y cultura. Narrativa colombiana del siglo XX. María Mercedes, Jaramillo et al. (Comp.). Bogotá: Ministerio de Cultura, 2000, pp.339-378.

Rancière, Jacques. El desacuerdo. Política y filosofía. Buenos Aires: Nueva Visión, 1996.

Richard, Nelly. Feminismo género y diferencia(s). Santiago de Chile: Palinodia, 2008.

Reyes, Yolanda. "En nuestro nombre: ¿Qué significa un país contado en masculino? ¿Qué discursos convencionales se siguen repitiendo?" El Tiempo, 6 de diciembre de 2017, https://www.eltiempo.com/opinion/columnistas/yolanda-reyes/ennuestro-nombre-sigo-escribiendo-148498. Octubre 30 de 2020

Sánchez, Gonzalo y Ana María Saavedra. "En buenaventura se agotó el diccionario de la violencia: Gonzalo Sánchez". El País, 7 de junio de 2015, https://www.elpais.com.co/judicial/en-buenaventura-se-agoto-eldiccionario-de-la-violencia-gonzalo-sanchez.html. Octubre 30 de 2020

Sklodowska, Elzbieta. Testimonio hispanoamericano: historia, teoría, poética. New York: Peter Lang, 1992.

Torrado, Santiago. Pilar Quintana "Los bandos de Petro y Duque están sacándose los dientes". El País, 16 de mayo de 2018. https://elpais.com/internacional/2018/05/15/colombia/1526400013_6471 69.html. Octubre 30 de 2020.

Tufano, Sara. "Venganza genocida ¿por qué se niega que el exterminio sistemático de líderes y exguerrilleros sea un genocidio?" El Tiempo, 29 de julio de 2020. https://www.eltiempo.com/opinion/columnistas/saratufano/venganza-genocida-columna-de-sara-tufano-523778. Octubre 30 de 2020.

Wahnón, Sultana. Kafka y la tragedia judía. Barcelona: Riopiedras. 2003.

(c) $\mathbf{E Y} \quad$ New articles in this journal are licensed under a Creative Commons Attribution 4.0 United States LiULIS D-Sonk cense. tal Publishing Program and is cosponsored by the University of Pittsburgh Press. 